\title{
DISCRICIONARIEDADE E ARBITRARIEDADE JUDICIAL NA PERSPECTIVA POSITIVISTA DE KELSEN E HART
}

\author{
$\%$ \\ Tamiris Alessandra Gervasoni \\ Universidade de Santa Cruz do Sul - UNISC - Brasil \\ Iuri Bolesina \\ Universidade de Santa Cruz do Sul - UNISC - Brasil
}

\section{Resumo}

Com auxílio do método dedutivo, o presente estudo investiga a evolução dos positivismos jurídicos em três momentos em virtude de eventuais inverdades e incertezas que envolvem o tema, bem como analisa a discricionariedade judicial, e sua distinção de arbitrariedade, em Kelsen e Hart. Desta forma, através do procedimento histórico crítico, efetua-se uma abordagem histórica e conceitual do positivismo exegético, analisando suas características e à relação destas com o período histórico ao qual pertence. Posteriormente, apresenta-se o positivismo normativista, com ênfase nas premissas kelsenianas e na discricionariedade judicial advinda deste momento do positivismo, no qual atribuir-se uma função criativa ao intérprete dentro da ideia de moldura da lei criada por Kelsen. Em seguida, a despeito de Hart traçar novos contornos ao positivismo jurídico neste terceiro momento, observa-se ainda a discricionariedade judicial como um problema na interpretação judicial além de sua distinção entre arbitrariedade. Neste sentido, diante dos aportes teóricos e conceituais investigados, percebeu-se que apesar de distintas, discricionariedade judicial e arbitrariedade, ambas não enfrentam a questão da impossibilidade de controle conteudístico da decisão judicial ao ficar à mercê da livre consciência do intérprete para decidir em cada caso concreto. Assim, a dedicação e esforço dos pensadores do direito devem manter-se concentrados na preocupação de "resolver" a discricionariedade judicial - e arbitrariedade, visto que sua presença não seria democrática e nem se coadunaria com a ordem constitucional ao criar o direito conforme uma subjetividade singular dentro de um sistema jurídico plural e democráticos.

Palavras-chave: Positivismo(s) jurídico. Discricionariedade judicial. Arbitrariedade. Kelsen. Hart.

\section{Introdução}

Orbitam sobre a temática do positivismo jurídico algumas inverdades e controvérsias, desde a sua origem enquanto positivismo exegético/legalista até a sua discutida nomenclatura 
de pós-(ou neo)positivismo. Em toda celeuma na qual o assunto é inundado há a companhia de dois renomados autores sobre o assunto, inicialmente Kelsen, como representante de maior expressão do positivismo normativista, e Hart, adjetivado de pós-positivismo (ou neopositivista), algo que também não se pode afirmar com veracidade. Diante de todas as falácias e discussões que envolvem o tema, o presente estudo propõe-se a investigá-lo desde sua origem até seu ponto de chegada em Hart, considerado como uma perspectiva mais atual e "soft" do positivismo.

Partindo-se da Escola da Exegese, compreendia como marco inicial do positivismo jurídico, em sua feição legalista, entre o final de século XVIII e início do séxulo XIX no período das grandes codificações, objetiva-se demonstrar a relação entre suas principais características com o período histórico em que é originada, visto que recebe influência direta dos ideais burgueses presente na época, bem como corresponde ao anseio de rompimento com o direito natural e com as normas religiosas.

Em um segundo momento apresentam-se algumas causas que corroboraram para o abandono do positivismo exegético, estabelecendo-se o positivismo normativa proposto essencialmente por Hanks Kelsen. A partir de então, uma nova função é atribuída aos juízes que poderão criar o direito a partir da figura da moldura da lei presente nesta fase do positivismo jurídico. Conjuntamente com estas novas características, novas complicações e questionamentos surgem no decorrer do desenvolvimento do positivismo normativista, especialmente no que tanga à discricionariedade judicial advinda com este momento do positivismo jurídico.

A discricionariedade judicial é tema polêmico e de grande preocupação no âmbito jurídico ainda na atualidade e, não obstante Kelsen seja o maior alvo de críticas neste aspecto, Hart também trabalha a discricionariedade judicial em suas obras, ainda que com contornos diferenciados. Além de uma reformulação do positivismo jurídico apresentado por Kelsen, Hart aprofunda o conceito de discricionariedade judicial distinguindo do conceito de arbitrariedade, que será abordado neste estudo.

Desta forma, apresenta-se inicialmente a evolução do positivismo jurídico em três momentos, inicialmente com o positivismo exegético, em seguida o positivismo normativista com ênfase no pensamento de kelseniano e como terceiro momento a reformulação de Hart, que apresenta algumas distinções em relação à Kelsen. Aborda-se ainda a discricionariedade judicial e a sua compressão nestes dois autores, observando as contribuições de cada um e as implicações que tal conceito traz em relação à intepretação judicial da lei. 


\section{A evolução do(s) positivismo(s) em três momentos}

Ao abordar-se o tema do positivismo jurídico é necessário considerar a existência de vários positivismos e a confusão que comumente ocorre entre eles e seus próprios conceitos. Não raramente vê-se o equívoco de resumir o positivismo à expressão “juiz boca da lei” aliado ao engano de imputar a autoria de tal frase a Kelsen no seu anseio pela "interpretação pura da lei”'. Esta premissa seguramente não demonstra a ampla complexidade e o desenvolvimento histórico do positivismo enquanto "teoria explicativa do fenômeno jurídico" (DIMOULIS, 2006, p. 66) bem como não alcança todas as fases a que tal fenômeno perpassou, remonta tãosomente ao considerado primeiro momento do positivismo, o positivismo exegético/legalista.

O surgimento do positivismo exegético/legalista está atrelado ao abandono do direito natural e a substituição das normas religiosas que existiam nas sociedades europeias da Idade Moderna, dando impulso às ideias racionalistas sobre a criação e a aplicação do direito juntamente com as grandes codificações do século XIX e XX. Tal circunstância em muito se deve ao anseio existente na época de não mais justificar o poder por motivos divinos concentrado unicamente no rei e, sim, iniciar um processo de vinculação do(s) governantes(s) às leis erigidas pela sociedade, que a partir de então apresentaram-se sob a forma de Códigos. Assim, "toda argumentação jurídica deve tributar seus méritos aos Códigos que passam a possuir, desse momento em diante, a estatura de verdadeiros "textos sagrados"”. (STRECK, 2012, p. 32).

Nesse sentido, a Escola da Exegese é originada na França, no final do século XVIII e início do século XIX, tendo como marco de maior expressão o Código Civil de Napoleão. A sua influência transpassou-se no tempo e espaço, fazendo-se presente na maioria dos países europeus continentais, sendo estudada e considerada significativamente até os dias atuais no âmbito jurídico (LIMA, 2008, p. 106). Em explicação abreviada pode-se compreender que a exegese enxergava nos Códigos a possibilidade de prever todas as situações sociais e relevantes juridicamente - exemplo disto é observado no Código Civil Prussiano de 1746 que contava com dezessete mil artigos (WIEACKER, 2010, p. 369-380) -, o que acarretava em uma interpretação resumida à literalidade da lei $^{2}$ prevista no Código, logo, a interpretação dos juízes à época consistia apenas na subsunção formal-dedutiva (FINGER, 2000, p. 88).

\footnotetext{
1 "E nisso reside a "maldição" de sua tese. Não foi bem entendido, quando ainda hoje se pensa que, para ele, o juiz deve fazer uma interpretação "pura da lei." (STRECK, Lenio Luiz, 2012, p. 87).

2 "O método exegético, que surgiu sob o signo do modelo napoleônico de direito, configura uma variedade interessante do método gramatical: para a determinação do sentido unívoco das palavras da lei constrói ele a ficção do espírito do legislador. Substancializa, assim, um ente ideal abstrato, logrando através dessa reificação a
} 
Em face deste método subsuntivo de intepretação literal da lei, e do dogma da completude no qual a lei abrangeria todas as possíveis situações jurídicas e suas respectivas resoluções, este primeiro momento do positivismo acredita ter alcançado seu propósito de exclusão de valores metafísicos da interpretação, bem como ter realizado a separação da moral e da política em relação ao direito, neste sentido, "o direito deixa de depender dos juízos de valor realizados pelos usuários das normas e das vicissitudes do poder" (BARZOTTO, 1999, p. 21).

Assim, ante a premissa de plenitude dos textos descritos nos Códigos, a intepretação objetivista $^{3}$, portanto, fiava-se na crença de que a própria lei (texto) trazia a norma em si, desconsiderando as diferenças de caráter ontológico existente entre ambas (LUIZ, 2013, p. 35). Deste modo, retomava-se a metafísica clássica, pois ponderava-se que a intepretação judicial era/é controlada pelas próprias regras (texto), visto que estas conteriam a real e única significação do texto, acreditava-se que a verdade estivesse nas "coisas" (LUIZ, 2013, p. 35), "que as leis conformam um universo significativo e auto suficiente, do qual se pode inferir por atos de derivação racional as soluções para todo tipo de conflito jurídico" (WARAT, 1979, p. 76).

Consagrada a Escola da Exegese no período da Revolução Francesa e da consolidação do Estado Liberal, tem-se que esta correspondia à ideologia burguesa da época ${ }^{4}$ e, assim, o método de interpretação da lei ao buscar encontrar o espírito do legislador ${ }^{5}$ na literalidade da lei - como se tal fosse possível ${ }^{6}$ - deparava-se com um legislador que preocupava-se notadamente com os ideais burgueses preterindo-se, por conseguinte, os interesses do restante da população, o que não mais atendia as novas demandas sociais e políticas presentes no final do século XIX e início do século $\mathrm{XX}^{7}$.

possibilidade de que o órgão aplicador objetive suas decisões, seus juízos de valor, apresentando-se como dados de uma vontade objetiva e, portanto, sujeito a verificação." (WARAT, 1979, p. 76).

3 "A tese objetivista representa um esforço para que seja deixada de lado, no momento da intepretação, qualquer influência valorativa do julgador. Tem por justificava que a interpretação judicial deve ocorrer com base em outros nortes que a vontade de um juiz. Para tanto, buscam-se minimizar as brechas normativas (o problema das lacunas) e maximizar as exigências institucionais para que os juízes decidam conforme os standards legais gerais por mera subsunção, num processo lógico-dedutivo." (LUIZ, 2013, p. 38).

4 "Corresponde a escola exegética ao típico modelo da ideologia burguesa construindo um sistema jurídico que prometia seguranças frente às arbitrariedades do absolutismo que a precedeu, e que se punha como fiadora das formas de desenvolvimento do capital. É neste que a Revolução Francesa é pensada como momento em que a escola alcançou sua personalidade". (WARAT, 1979, p. 77).

5 "Na práxis, o problema que essa metodologia acabou tendo que enfrentar foi referente à identificação de quem é especificamente legislador, quem deve ter o seu espírito descoberto". (MAZOTTI, 2010, p. 56).

6 "A pluralidade de intenções aliada aos acordos políticos realizados para a promulgação da lei impedem o intérprete de precisar o sentido da norma [...]”. (MAZOTTI, 2010, p. 58).

7 "[...] em uma sociedade mais simples, com um direito menos complexo, nos moldes da que os positivistas exegetas tentavam descrever, por exemplo, há maiores possibilidades de "acordo" acerca da conotação e da denotação do texto diante do caso concreto" (GERVASONI, BOLESINA, 2014, p. 178) 
[...] a pretensão de um método imparcial e equânime (o exegético) se revelou como uma forma de manutenção do status quo, a partir da mentalidade conservadora de manter o sistema jurídico totalmente atrelado ao Parlamento e inibindo qualquer ato criativo de entes externos à política legislativa. (MAZOTTI, 2010, p. 59).

Nesse período e contexto históricos, os modelos de codificação e os métodos sintáticosemânticos de interpretação começaram a se desgastar também em face da percepção que os Códigos não eram capazes de prever todas as situações do mundo concreto, que se apresentava cada vez mais plural e complexo. A falência do positivismo exegético, muito em razão da “impossibilidade de um fechamento semântico" (STRECK, 2010, p. 83) dá lugar a um segundo momento do positivismo, o positivismo normativista, que diante de tal impossibilidade reduz o problema da interpretação jurídica não ao modo como oz juízes decidem "mas, simplesmente, nas condições lógico-deônticas de validade das normas jurídicas (STRECK, 2010, p. 83).

Como maior expoente do positivismo normativista tem-se Kelsen com sua obra intitulada Teoria Pura do Direito. Esta obra eclode em um cenário caracterizado "pela pretensão de objetividade e cientificidade do Direito (especialmente tendo em vista o antiformalismo das escolas que povoaram o século XIX e o começo do século XX) e, de outro, pelos anseios (sobretudo burgueses) de segurança jurídica" (GERVASONI, 2013, p. 479). A despeito de se ter consciência acerca da relevância e influência da obra ora referida, tem-se também lucidez de que o presente trabalho não possui a impraticável pretensão de esgotar e aprofundar diversos de seus aspectos, contudo, pretende-se pontuar rapidamente algumas das suas caraterísticas no item subsequente e ater-se especificamente à questão da discricionariedade judicial, que é o foco deste estudo.

Em um terceiro momento é válido ressaltar as contribuições de Hart em sua reformulação do positivismo, considerando que tal autor, classificado por alguns como póspositivista e por outros como soft positivista, entende que essas classificações decorrem de alguns aspectos de sua obra. A primeira em razão do espaço da discricionariedade conferido aos tribunais pelo autor ${ }^{8}$ e a segunda por incorporar princípios morais ou valores substantivos como critérios de validade jurídica na regra de reconhecimento (HART, 2009, p. 323).

Hart reformula o positivismo jurídico em uma teoria jurídico-analítica ao "introduzir na descrição de um sistema normativo a noção de que o mesmo se fundamenta numa prática social

\footnotetext{
8 "Teorias modernas, como a de Neil MacCormick em sua obra L.A Hart, chegam a classificá-lo como um possível pós-positivista, dado o espaço de discricionariedade que o mesmo teria atribuído a um Tribunal. No entanto, ressaltamos novamente: na maioria dos manuais sobre teoria do direito no Brasil estão os referidos positivistas Kelsen e Hart, influenciando nossos conceitos sobre norma fundamental, normas primárias e secundárias e tantos outros". (BITTENCOURT; CALATAYUD; RECK, 2014, p. 20).
} 
institucionalizada de aceitação das regras" (BITTENCOURT; CALATAYUD; RECK, 2014, p. 54). Ao construir um sistema jurídico de regras organizadas hierarquicamente vê-se sua aproximação com Kelsen, todavia, ao permitir reflexos da prática social em seu sistema de normas, para reconhecer a validade de regras, a partir de algo que não seja o próprio direito, há um afastamento entre os autores, visto que "ao trazer para a esfera da regra de reconhecimento os fatos sociais, a "pureza" almejada por Kelsen é substituída em razão de uma realidade empírica exterior a ela" (BITTENCOURT; CALATAYUD; RECK, 2014, p. 78). Hart prevê um sistema jurídico escalonado em normas primárias e secundárias ${ }^{9}$, dentre as secundárias existindo três espécies de regras: de reconhecimento, de modificação e de julgamento ${ }^{10}$. Será na regra de reconhecimento que ocorrerá a inserção da prática social no âmbito normativo, pois esta "advém da prática social compartilhada, inclui juízes e cidadãos numa cooperação que legitima a autoridade criada" (BITTENCOURT; CALATAYUD; RECK, 2014, p. 94).

A regra de reconhecimento que especifica os critérios últimos empregados para a identificação do direito não escapa daquilo que Hart denominou de textura aberta, ou seja, uma margem de imprecisão que afeta todas as regras. Esta margem de imprecisão e incerteza das regras é algo inerente à própria natureza da linguagem e tais podem ser diminuídas mas não eliminadas através dos cânones da linguagem, pois estes mesmos carecem também de interpretação e da mesma forma como ocorre com as regras não oferecem sua própria interpretação (HART, 2009, p. 164). Neste espaço de textura aberta, no qual subsunção e silogismo já não resolvem as questões postas pela necessidade de interpretação, o poder da discricionariedade é muito amplo, constituindo-se numa escolha que poderá ser irracional ou até mesmo arbitrária (HART, 2009, p. 165).

Do surgimento do positivismo exegeta para um segundo momento no positivismo normativista kelseniano é perceptível neste que o juiz está longe de ser "a boca da lei”, como

\footnotetext{
9 “As primárias dizem respeito a obrigações impostas aos destinatários dessas normas. As secundárias, por sua vez, situam-se em um nível diferente do das primárias, pelo fato de terem por objeto, não obrigações, mas as próprias normas primárias. Ou seja, as normas secundárias especificam as normas primárias, pois são as secundárias que determinam, introduzem, eliminam e alteram as normas primárias". (BOLESINA; DIAS, 2014, p. 56).

10 “As normas secundárias são de reconhecimento, quando especificam as condições para que uma norma primária possa ser assim considerada e se torne obrigatória, o que, em um sistema jurídico evoluído, pode ocorrer pelo fato de as normas primárias terem sido aprovadas pelo órgão competente ou por terem sido o resultado de uma longa prática consuetudinária ou, ainda, por sua relação com uma decisão judicial. As normas secundárias são, por outro lado, de modificação, nos casos em que disciplinam os mecanismos para a modificação ou a revogação de uma norma primária ou para a introdução de uma nova norma primária. Por fim, há ainda as normas secundárias de julgamento que outorgam a determinadas pessoas o poder de julgar as violações às normas primárias. Hart observa que há uma estreita ligação entre as normas secundárias de modificação e de julgamento com as normas secundárias de reconhecimento, pois, invariavelmente, a presença das primeiras implica a da última, a de reconhecimento. (BOLESINA; DIAS, 2014, p. 56-57).
} 
ocorre inicialmente. Não mais atrelado à literalidade da lei, ao juiz agora caberia uma atividade criativa, desamarrado da expressão literal do texto mas encadeado pela moldura da norma geral, representada pelo próprio texto, o juiz de forma relativamente livre poderia criar o direito. Diante das opções apresentadas pela moldura, o problema da intepretação centrar-se-ia na semântica e não na sintática, gerando várias possibilidades de respostas adequadas ao caso concreto. Esta margem de imprecisão e incerteza das regras que seria algo inerente à própria natureza da linguagem é também considerada por Hart, permanecendo, portanto, também neste terceiro momento do positivismo a questão da discricionariedade, que será objeto de estudo específico em item futuro.

\section{A discricionariedade judicial em kelsen na moldura da lei}

Evidentes são as contribuições de Kelsen na constituição dos ordenamentos jurídicos ocidentais que, em geral, baseiam-se na estrutura piramidal hierarquizada do ordenamento jurídico pela qual fixam-se os critérios de juridicidade e de validade, destarte, "num sentido jurídico-positivo, fonte do Direito só pode ser o Direito” (KELSEN, 1998, p. 163), “ou seja, o fundamento de validade de uma norma válida somente pode ser outra norma válida, de onde se fala que o positivismo inaugura a noção de autoprodução do direito" (GERVASONI, 2013, p. 478).

A autoprodução do direito relaciona-se com o propósito de uma ciência autônoma do direito, almejada por Kelsen, pois se assim o fosse, o direito seria independente de outras ciências, bem como da moral e da política, no entender do autor, a validade da própria ordem jurídica deveria ser(/é) independente da sua (dis)concordância com qualquer sistema moral (1998, p. 48). Neste sentido, o próprio estudo do Direito deveria privar-se da influência de valores metafísicos e fontes extrajurídicas, contudo, é necessário ressalvar que Kelsen "não ignorou a carga valorativa que informa o fato jurídico, mas simplesmente ressaltou a necessidade de o fenômeno jurídico ser analisado como tal; independentemente de outras áreas do conhecimento". (FERNANDENS; BICALHO, 2011, p. 108).

Neste sentido, sendo o direito autônomo e, portanto, somente uma norma válida é que tornará outra norma válida, mantendo-se a lógica de autoprodução do direito, tem-se que em algum momento "a cadeia formada por normas superiores (reguladoras) e inferiores (reguladas) deve encontrar um limite nesta busca pelo fundamento de validade, sob pena de tornar inviável a delimitação do Direito" (BITTENCOURT; CALATAYUD; RECK, 2014, p. 44). Para esta 
questão, Kelsen propõe a existência de uma norma fundamental que constitui o fundamentado de validade e de unidade da ordem normativa.

\begin{abstract}
A norma fundamental é a fonte comum da validade de todas as normas pertencentes a uma e mesma ordem normativa, o seu fundamento de validade comum. $\mathrm{O}$ fato de uma norma pertencer a uma determinada ordem normativa baseia-se em que o seu último fundamento de validade é a norma fundamental desta ordem. É a norma fundamental que constitui a unidade de uma pluralidade de normas enquanto representa o fundamento da validade de todas as normas pertencentes a essa ordem normativa. (1998, p. 136).
\end{abstract}

A norma fundamental é a instauração do fato fundamental da criação jurídica, não sendo uma norma positiva, mas uma norma pressuposta tida como a mais elevada e, portanto, não é resultado de uma descoberta ou criação. Para a Teoria Pura do Direito, a norma fundamental tem como função fundamentar a validade objetiva de uma ordem jurídica positiva (normas postas), interpretando o sentido subjetivo destes atos como seu sentido objetivo. A norma fundamental, de acordo com a referida teoria, faz com que os juristas interpretem o sentido subjetivo como norma objetivamente válida não carecendo recorrer a fundamentos metafísicos ${ }^{11}$.

Dentre outros aspectos não menos relevantes do autor ora abordado, pode-se sintetizar sua obra, portanto, na tentativa de desenvolver o direito enquanto uma ciência autônoma, reiterando o método analítico e aperfeiçoando o “" "rigor” lógico do trabalho científico proposto pelo positivismo"12 (STRECK, 2012, p. 32). O positivismo normativista de Kelsen tem sua maior dificuldade no abandono do "principal problema do direito: a interpretação concreta, no nível da "aplicação" ((STRECK, 2012, p. 34), permitindo abertura para uma discricionariedade judicial de difícil (impossível?) controle. A discricionariedade em Kelsen é notada a partir da

\footnotetext{
11 "Concebida à semelhança de um postulado científico, a norma fundamental pode realizar com sucesso sua função básica, muitas vezes obscurecida pelo intenso ataque que lhe é dirigido: evitar a regressão infinita na busca pela validade do direito, permitindo a clausura do sistema diante dos fundamentos externos - a vontade de Deus, a razão abstrata humana, o poder, a concordância social etc. - que comumente são utilizados para fundamentar as ordens jusnormativas, remetendo-as a esferas não-jurídicas de validade e, por isso mesmo, não-autônomas e ideologicamente comprometidas". (MATOS, 2011, p. 69).

12 "Kelsen não quer destruir a tradição positivista que foi construída pela Jurisprudência dos Conceitos. Pelo contrário, é possível afirmar que seu principal objetivo era reforçar o método analítico proposto pelos conceitualistas de modo a responder ao crescente desfalecimento do rigor jurídico que estava sendo propagado pelo crescimento da Jurisprudência dos Interesses e da Escola do Direito Livre - que favoreciam, sobremedida, o aparecimento de argumentos psicológicos, políticos e ideológicos na interpretação do direito. Isso é feito por Kelsen a partir de uma radical constatação: o problema da interpretação do direito é muito mais semântico do que sintário". (STRECK, 2012, p. 33).
} 
moldura conformada pelas normas gerais na interpretação das leis ${ }^{13}$ dentro da qual o intérprete é livre para a sua apreciação ${ }^{14}$ - em sua obra Teoria pura do Direito, no capítulo VIII.

Salienta-se que o positivismo enquanto postura científica ao intitular-se de tal modo referia-se inicialmente à expressão "positivo" no sentido de fatos, a algo concreto que fosse passível de correspondência a uma realidade mensurável, medível, e, por isso, seu apego inicial se dá com as leis sistematizadas em Códigos. Desde o seu surgimento já residia a preocupação com a interpretação judicial da lei que neste momento era realizada de modo sintático, portanto, "a simples determinação rigorosa da conexão lógica dos signos que compõem a "obra sagrada" (Código) seria o suficiente para resolver o problema da interpretação do direito" (STRECK, 2010, p. 85).

Com a evolução do positivismo, que num segundo momento é epitetado de normativista, o problema da interpretação da lei mantém-se, porém, com nova roupagem. O enfoque agora será mais na semântica do que na sintática em virtude de que, para Kelsen, a norma jurídica não equivale ao texto da lei, mas sim, será criada a partir da moldura semântica constituída pelo texto legal (STRECK, 2010, p. 85). A dificuldade surge, em grande medida, justamente porque uma palavra, ou uma sequência de palavras, possui uma pluralidade de significados e Kelsen reconhece isso afirmando que "o sentido verbal da norma não é unívoco, o órgão que tem de aplicar a norma encontra-se perante várias significações possíveis” (1998, p. 249).

Neste sentido, dentre as várias significações possíveis, basta que elas se mantenham dentro da moldura - sendo que esta também passa pelo julgamento do intérprete, pois se as palavras não possuem sentido unívoco, ele que atribuirá sentido a elas formando a sua própria moldura - que estarão em conformidade com o Direito, visto que "a interpretação de uma lei não deve necessariamente conduzir a uma única solução como sendo a única correta, mas possivelmente a várias soluções que - na medida em que apenas sejam aferidas pela lei a aplicar - têm igual valor" (KELSEN, 1998, p. 247).

Estas várias soluções possíveis ao caso concreto teriam o mesmo valor por justamente estarem todas dentro de uma mesma moldura, e que só por isso já estariam em conformidade com o Direito. É nesta premissa de "moldura" que defensores da discricionariedade judicial kelseniana, em geral, argumentam não haver uma atividade demasiadamente livre do intérprete

\footnotetext{
13 "Para Kelsen, as normas gerais estabelecem uma moldura em que, no seu interior, podem ser verificadas várias possibilidades de aplicação51. Quando o juiz aplica o Direito, pode optar por mais de um sentido autorizado pela norma. Contudo, Kelsen é enfático quando afirma que não há uma única vinculação a ser determinada dentro da moldura, mas uma "pluralidade de determinações a fazer [...]". (BITTENCOURT; CALATAYUD; RECK, 2014, p. 49).

14 "Relativamente a este, a produção do ato jurídico dentro da moldura da norma jurídica aplicada é livre, isto é, realiza-se segundo a livre apreciação do órgão chamado a produzir o ato." (KELSEN, 1998, p. 249).
} 
da lei. Ocorre que, a despeito de Kelsen ter pensado em "limites" para a atividade interpretativa do julgador ao fixá-la dentro da moldura, esta mesma não escapa do subjetivismo do intérprete, em virtude de que ele próprio constrói a sua moldura.

[...] nem mesmo a criação da moldura afasta o completo arbítrio do intérprete. Primeiro, porque é ele mesmo quem cria a o quadro, ou seja, remontando a própria filosofia da consciência, na subjetividade do próprio intérprete é que haverá distinção de qual das interpretações estarão dentro da moldura e quais permanecerão fora dela, demonstrando, claramente, como o método, dentro do conhecimento apresenta-se como momento máximo da subjetividade do intérprete. (LUIZ, 2013, p. 50).

Tal moldura estabelece a competência para a produção da norma jurídica individual, sem fixar o seu conteúdo, sendo que o intérprete não descobre um direito acabado, "já pronto", mas, em tal concepção, a própria decisão judicial consiste num processo de criação jurídica, não sendo as decisões judiciais apenas simples declarações do direito posto, mas sim, a continuação do processo de criação jurídica. Neste sentido, a interpretação é uma operação que acompanha o processo de aplicação do direito (KELSEN, 1998, p. 387) descobrindo-se qual o conteúdo terá a norma individual no caso concreto através da decisão judicial, ou seja, será direito aquilo que o interprete entender(compreender) que é o direito.

Desta forma, a primeira manifestação da discricionariedade judicial se dá em Kelsen, no capítulo VIII de sua obra Teoria Pura do Direito, diante da sua proposição de "moldura", a partir da qual abre-se um espaço de livre escolha para o julgador em sua interpretação judicial da lei, considerando, assim, a decisão judicial como ato de vontade do julgador ${ }^{15}$. Sinteticamente, a interpretação para Kelsen constitui-se na "fixação por via cognoscitiva do sentido do objeto interpretar" (1998, p. 247) apoiando-se na "estrutura sujeito-objeto, típico de uma doutrina neokantista, que fica dependente, portanto, da filosofia da consciência" (LUIZ, 2013, p. 47).

\footnotetext{
15 “Aos olhos kelsenianos, o magistrado está longe de ser o escravo da lei, ou seja, em nada se assemelha ao juiz la bouche de la loi; pelo contrário, ele decide por ato de vontade, porque não há um critério - ou mesmo um macrocritério - para distinguir, entre as possibilidades possíveis de interpretação, aquela que deve ser aplicada ao caso. Por isso, a busca por uma resposta correta, para Kelsen, não está circunspecta à teoria do Direito, mas se trata de um problema de política do Direito. Assim, a sentença - e genericamente qualquer ato de aplicação - é um puro ato voluntarista do juiz, que, de forma subjetiva, escolhe, entre várias possibilidades, aquela que lhe aprouver. O juiz, portanto, é um criador do Direito e também ele é, nesta função, relativamente livre”. (LUIZ, 2013, p. 49).
} 


\section{A discricionariedade em hart e sua distinção de arbitrariedade}

Não obstante as distinções apontadas entre Kelsen e Hart no item anterior, foi perceptível a aproximação em algumas de suas ideias e dentre elas uma é a discricionariedade também presente na obra de Hart, ainda que tenha auferido contornos distintos. Diversamente da figura da "moldura" observada na obra de Kelsen, Hart constrói a ideia de textura aberta do próprio direito, ou seja, aéreas de conduta que foram deixadas para serem desenvolvidas pelos tribunais e que devem alcançar equilíbrio entre os interesses conflitantes que diferem em peso, de caso para caso (2009, p. 175).

Neste espaço de textura aberta, na qual subsunção e silogismo já não resolvem as questões postas pela necessidade de interpretação, Hart admite a função criadora dos tribunais afirmando que tais espaços abertos devem ser ocupados pelo poder discricionário, construindose padrões precisos diante daquilo que inicialmente era vago. ${ }^{16}$ Entretanto, o próprio autor admite que o poder da discricionariedade é muito amplo, podendo constituir-se numa escolha que poderá ser irracional ou até mesmo arbitrária (2009, p. 165).

Constata-se que para tal autor discricionariedade judicial e arbitrariedade não devem ser tomadas como sinônimos, bem com, não é correto confundir discricionariedade judicial com discricionariedade administrativa, como se passará a distinguir a título de melhor elucidação e didática. Na discricionariedade administrativa ao agente é permitido por previsão legal que escolha os meios necessários para alcançar os objetivos pretendidos, tendo em vista que tal ato estará sujeito a revisão em observação ao princípio da legalidade ${ }^{17}$. Enquanto que na discricionariedade judicial, o julgador cria o direito - e nisto Kelsen e Hart estão de acordo diante da inexistência de regra aplicável ao caso concreto. Em resumo, na discricionariedade administrativa o ato perfaz-se em consequência de uma autorização legislativa, já no âmbito da discricionariedade judicial ocorre o inverso, o julgador cria uma regra por inexistir regulamentação legal cabível em tal caso concreto. ${ }^{18}$

\footnotetext{
16 “[...] sempre haverá, em qualquer sistema jurídico, casos não regulamentados juridicamente sobre os quais, em certos momentos, o direito não pode fundamentar uma decisão em nenhum sentido, mostrando-se o direito, portanto, parcialmente, indeterminado ou incompleto. Para que possa proferir uma decisão em tais casos, o juiz não deverá declarar-se incompetente nem remeter os pontos não regulamentos ao poder legislativo para que este decida, como outrora defendia Bentham, mas terá de exercer sua discricionariedade e criar o direito referente àquele caso, em vez de simplesmente aplicar o direito estabelecido já existente". (HART, 2009, 351).

17 "[...] a discricionariedade resulta da expressão atribuição normativa à autoridade administrativa, e não da circunstância de os termos das normas jurídicas serem ambíguos, equívocos ou suscetíveis de receber especificações diversas". (GRAU, 1998, p.164).

18 "Ocorre que, no âmbito da interpretação judicial não nos encontramos diante da mesma situação. Aqui não há regulamentação a ser discutida. Pelo contrário, pressupõe-se que ela inexiste". (STRECK, 2012, p. 41).
} 
Considerando esta atividade criativa do juiz Hart acolhe o poder discricionário, todavia, ressalva que este não deve transmutar-se em um poder arbitrário, entendendo, portanto, que discricionariedade não equivale à arbitrariedade. Ao lecionar que o juiz pode exercer seu poder de criar o direito, porém, não de modo arbitrário, o autor expressa que para não fazê-lo de tal forma o juiz deve "ser sempre capaz de justificar sua decisão mediante algumas razões gerais", atuando de forma semelhante à atuação de um legislador consciente, decidindo de acordo com suas próprias convicções e valores. (2009, p. 352). Desta forma, a discricionariedade estaria em um plano intermediário entre arbitrariedade e aplicação literal da lei - determinate rules (SHAW, 2013, p. 701), sendo que tais distinções não são apresentadas na obra de Hart, mas foram encontradas em um ensaio considerado perdido, publicado mais tarde pela Universidade de Harward $^{19}$.

Ao lecionar sobre a distinção entre arbitrariedade e discricionariedade, Hart mencionava o caráter indeterminado das leis/regras, que este seria totalmente compatível com o Estado Democrático de Direito (rule o law) desde que o método escolhido para solucionar esta indeterminação comportasse racionalmente padrões previamente estabelecidos (standards), o que não seria, em seu entendimento, algo arbitrário, pois a discricionariedade faria parte da própria lei e para ser aperfeiçoada não deveria ser observada como um obstáculo à lei (SHAW, 2013, p. 669), mas associada à ideia de que as leis são feitas por homens, logo, não são perfeitas, e por vezes, serão indeterminadas (HART, 2009, p. 143).

For Hart, legal systems inherently contain spheres of indeterminacy. There are inevitably gaps in the law, and officials making decisions have to fill those gaps. When they do so, Hart argued, legal officials ought to exercise discretion rather than arbitrary choice or whim. (SHAW, 2013, p. 695-696).

Diante desta indeterminação, trazendo consigo a responsabilidade de múltiplas possíveis soluções ao caso concreto, é que Hart expunha a discricionariedade nestas situações não como mera escolha ou satisfação de um desejo pessoal - o que seria arbitrário em sua concepção - mas como uma virtude intelectual, torando possível, com sagacidade e prudência, o discernimento dentre estas várias soluções qual seria mais apropriada (SHAW, 2013, p. 698699). Exemplificando, Hart ilustrava a partir da seguinte situação ${ }^{20}$ : ““Você prefere martini ou

\footnotetext{
19 "This Essay analyzes an essay by H. L. A. Hart about discretion that has never before been published, and has often been considered lost. Hart, one of the most significant legal philosophers of the twentieth century, wrote the essay at Harvard Law School in November 1956, shortly after he arrived as a visiting professor. In the essay, Hart argued that discretion is a special mode of reasoned, constrained decisionmaking that occupies a middle ground between arbitrary choice and determinate rule application.” (SHAW, 2013, p. 666).

20 "To illustrate, Hart asked his audience to confront a dilemma that weighed heavily on the legal process generation: "Will you have a Martini or a sherry?"200 Specifically, how would you defend your choice from
} 
sherry"? "Você escolhe Martini e eu pergunto por que?" Você, então, responde "por que eu acho melhor - só por isso'. Para Hart, este não é um exercício da discricionariedade" (SHAW, 2013, p. 699).

Ao agir deste modo, não houve nenhum princípio que justificasse a escolha realizada bem como não houve a menor tentativa de justificá-la racionalmente. A escolha, portanto, não configurou-se em um exercício da discricionariedade porque não é passível de uma defesa racional baseada em princípios, caso contrário, se fosse possível defender racionalmente a opção pelo martini, talvez houvesse um exercício da discricionariedade (SHAW, 2013, p. 699).

Outra forma extrema de decisão, além da arbitrariedade em Hart, seria a aplicação literal/crua da lei, denominada de determinate application of rules. Nesta haveria a mera aplicação mecânica da lei, assim, "the simply apply rules mechanically in a way that provides a correct answer in every case" (SHAW, 2013, p. 699). Neste sentido, em uma situação na qual a regra fosse clara, determinando especificamente o que realizar no caso concreto, trazendo um sentido unívoco, seria um equívoco classificá-la como uma situação na qual houve um exercício discricionário $^{21}$. Todavia, Hart rejeitava este formalismo e, conforme referido anteriormente, não acreditava no sentido unívoco das leis/regras, portanto, não acreditava no método dedutivo para a solução dos casos concretos (SHAW, 2013, p. 700).

Entre os extremos da arbitrariedade e da determinate application of rules, residiria a discricionariedade, figurando como um modo de decidir intermediário que Hart procura explicar por meio do seguinte exemplo ${ }^{22}$ : uma jovem anfitriã irá receber seus primeiros convidados para um jantar, para esta ocasião ela precisa decidir se usará suas melhores facas que são de prata antiga, muito bonitas e que irão combinar com a toalha e os copos. Por outro lado, elas são pesadas e difíceis de manejar, não são muito afiadas e seu esplendor pode ser compreendido como ostentação (SHAW, 2013, p. 702).

\footnotetext{
criticism? "You choose a martini, and I ask why," Hart supposed; "you reply, 'Because I like it better - that's all.'”201 This choice, for Hart, is not an exercise of discretion". (SHAW, 2013, p. 699).

21 "To illustrate, Hart invited his audience to consider yet another puzzling predicament: sharpening a pencil. "I go to the drawer and I am faced with a knife, three spoons, and two forks." In the end, "I choose a knife: if asked why, I would not here reply, 'Because I like it,' but perhaps, 'Because I want to sharpen a pencil and this is the obvious way to do it." "In this case, Hart suggested, there is a correct answer.And where there is a correct answer, the word "discretion" seems out of place. "[I]t seems to me absurd to speak of a choice of a knife as an exercise of discretion," Hart said; "it was the only sensible thing to do." Hart generalized from the example to conclude: "[W]hen our aims are as determinate as this and the situation is as clear as this and the proper thing to do is patent to the elementar knowledge of what will produce what, we choose indeed correctly but not in the exercise of discretion." (SHAW, 2013, p. 700).

22 "A young hostess is giving her first dinner party and the question arises, shall she use for this occasion the best knives: they are old silver, very beautiful, and they will set off the snowy tablecloth and the glasses. On the other hand, they are undoubtedly heavy and somewhat difficult to handle: they are not a bit sharp, and also their splendour might be thought a little bit showy by some". (SHAW, 2013, p. 702).
} 
A partir deste exemplo, o esforço da jovem em decidir pela utilização ou não das facas é comparado ao exercício da discricionariedade judicial, visto que a jovem anfitriã precisa ponderar todas as possíveis circunstâncias e consequências a partir da sua decisão, considerando pontos negativos e positivos, além da realização desta ponderação, ela procura opinião de outras pessoas, as quais ela acredita que possuam sabedoria para ajudá-la, confrontando, assim, suas ponderações com as delas. De acordo com Hart, o esforço da jovem ilustra as seis faces que a discricionariedade apresenta enquanto fenômeno:

First, there is no "clear right" decision. Second, "It]here is not a clear definable
aim" at a helpful level of specificity, though some outcomes, including "the
discomfort of the guests" and the "ugly appearance of the table," maybe obviously
bad. Third, the exact consequences of each possible decision are not clear. Fourth,
Fifth, words like "wise" and "sound" make more sense to describe discretionary
decisions than do words like "right" or "wrong." Sixth, Hart believed that
discretionary decisions are defended in two different ways if they are called into
question: justification and vindication. (SHAW, 2013, p. 701-702).

Em face do exposto, vê-se que para Hart, discricionariedade judicial e arbitrariedade não são sinônimos. Dentre as características apresentadas pode-se salientar que a primeira segue um padrão pré-existente (standards), que irá preencher um espaço deixado pela própria lei, configurando uma virtude intelectual relacionada à capacidade de discernimento (SHAW, 2013, p. 698-699), ademais, trará sempre uma justificativa racional e será passível de defesa racional com base em princípios (SHAW, 2013, p. 699). Já a arbitrariedade, além de inadequarse a um padrão prévio (standards) - ou até mesmo ir de seu encontro -, consiste numa escolha (ou capricho) que satisfaz um desejo pessoal, sem justificativa e, por conseguinte, não possui defesa racional (SHAW, 2013, p. 699).

Verifica-se, contudo, que a despeito da distinção entre arbitrariedade e discricionariedade judicial, se esta for exercida de modo irracional ou ilimitado poderá vir a se transformar em arbitrariedade, algo que até mesmo Hart reconhece (2009, p. 165). Neste sentido, apesar de traços bem distintos, a separação entre ambas pode apresentar-se em uma linha tênue, aliás, podem muito bem confundirem-se, conforme Streck avalia que ocorre no cenário jurídico brasileiro, no qual o sentido da discricionariedade percebido em Hart vai muito além pois “em qualquer 'espaço' de sentido - vaguezas, ambiguidades, cláusulas 'abertas' etc. -, o imaginário dos juristas vê um infindável terreno para o exercício da subjetividade do intérprete" (2012, p. 43).

A discricionariedade, assim como a arbitrariedade, traz em si o problema da falta de controle conteudístico (STRECK, 2012, P. 47), sendo que o subjtevismo do intérprete estaria 
presente em ambas. Assim, na arbitrariedade essa percepção se daria de modo mais explícito por justamente estar em desconformidade com um padrão prévio, ou seja, desviando de toda uma história jurisdicional construída de modo escancarado enquanto que, na discricionariedade, por meio de subterfúgios esta percepção demandaria maiores esforços interpretativos e investigativos, por estar na "conformidade da lei (moldura/textura aberta)".

Não obstante tal distinção mereça reconhecimento teórico e didático, pois enfatizada por autores célebres como Hart, se levada para o plano prático, no cenário jurídico brasileiro, parece não ter sentido no momento em que ambas consideram a própria intuição do julgador para decidir o caso concreto conforme sua consciência. Desta forma, nem arbitrariedade nem discricionariedade, sejam distintas ou não, conforme posicionamento adotado, estão em conformidade com o Estado Democrático de Direito brasileiro, pois não se pode aceitar a subjetividade de uma única pessoa na construção de uma história jurisdicional constitucional diante da uma Constituição erigida democraticamente, não se pode aceitar a "substituição do Direito por aquilo que o intérprete acredita que o Direito é"23 (LUIZ, 2013, p. 40).

\section{Conclusão}

O positivismo jurídico, enquanto fenômeno teórico e científico que atravessa as teorias jurídicas há mais de dois séculos, apresenta distintas características de acordo com cada período histórico, sendo, portanto, mais adequado falar-se em positivismos jurídicos. Dentre os positivismos jurídicos, ao adjetivado de exegético/legalista é que corresponde a afamada frase “juiz boca da lei” equivocadamente atribuída a Kelsen pelo senso comum, visto que este autor representa momento posterior do positivismo exegético/legalista, o normativista.

\footnotetext{
${ }^{23}$ Neste sentido, é válido mencionar crítica atual realizada por Streck a partir da "afirmada jurisprudência no sentido de que em casos de coexistência de relação conjugal e extraconjugal, tanto a mulher como a companheira devem receber a pensão, determinando que a pensão por morte de um homem seja dividida entre sua mulher $e$ seu amante". Tal decisão não encontra respaldo nem na Constituição nem no Código civil ao referir-se a um caso de concubinato adulterino, o que não confere direito algum na ordem jurídica brasileira. Este caso é apenas um dos exemplos em que faz-se uso da discricionariedade judicial - ou arbitrariedade, conforme posicionamento adotado - para decidir-se conforme, e apenas, à própria consciência. "Cada um decide como quer. Cada um busca o seu justo. Inventam-se "princípios" como o da conexão para poder encontrar o Santo Graal da justiça: o "princípio da verdade virtual", vasculhando no mundo virtual o que não foi demonstrado no mundo...real. Ao demais, concede-se usucapião de terras públicas, em flagrante violação dos limites semânticos da Constituição. Concedem-se meses a mais de licença maternidade. Em nome de sentimentos de afeto, amor, etc - e não de princípios ou regras - faz-se uma livre investigação do direito. Poderia elencar um enfiada de decisões contralegem, resultantes dessa revificação desse tipo de doutrina interpretativa ("tipo" Escola do Direito Livre, Realismo Jurídico, Livre Investigação, etc). E assim também se ensina. Nos cursos preparatórios, é comum que os professores digam: se for concurso para o MP, diga isso; se for para a Defensoria, aquilo; e, se for para a Magistratura, bem, aí tanto faz, contanto que você "fundamente" (sic). Preciso dizer mais?" (2015).
} 
No positivismo normativista kelseniano, afastado do apego à literalidade da lei, ao intérprete agora atribui-se a função criadora do direito, atrelado à moldura conjecturada pela lei. Dentro de tal moldura este será livre para decidir conforme sua consciência - o que fica bem claro no capítulo VIII da obra Teoria Pura do Direito, de Kelsen - e a partir daí problemas na interpretação judicial da lei começam a adquirir novos contornos projetados especialmente na discricionariedade judicial.

A discricionariedade judicial é tema também abordado por Hart que, a despeito de reformular vários aspectos do positivismo jurídico kelseniano, aprofunda o seu estudo trazendo uma distinção de tal conceito entre arbitrariedade. Do exposto percebeu-se que a distinção entre ambas é de relevância teórica e científica, mas quanto aos seus possíveis resultados práticos tais resumiriam-se em uma maior facilidade no reconhecimento da arbitrariedade ao destoar de um padrão previamente estabelecido na ordem normativa, enquanto que a discricionariedade ficaria conectada aos standards judiciais.

Neste sentido, tanto arbitrariedade como discricionariedade judicial seguem apresentando-se como dificuldades na interpretação judicial da lei, seja em sua concepção kelseniana ou hartiana, visto que ambas não são passíveis de um controle conteudístico, ficando a cargo do intérprete (juiz) decidir o que é o direito conforme sua consciência em cada caso concreto. Assim, a dedicação e esforço dos pensadores do direito ainda mantêm-se direcionados na preocupação de "resolver" a discricionariedade judicial - e arbitrariedade, visto que sua presença não seria democrática e nem se coadunaria com a ordem constitucional ao criar o direito conforme uma subjetividade singular dentro de um sistema jurídico e Constituição plurais e democráticos.

\section{Referências}

BARZOTTO, Luiz Fernando. O positivismo jurídico contemporâneo. São Leopoldo: Editora Unisinos, 1999.

BITENCOURT, Caroline Müller; CALATAYUD, Eduardo Dante; RECK, Janriê Rodrigues. Teoria do Direito e Discricionariedade: fundamentos teóricos e crítica ao positivismo. Santa Cruz do Sul: Essere nel Mondo, 2014.

BOLESINA, Iuri; DIAS, Felipe da Veiga. A decisão judicial mais adequada à "Constituição personificada" no atual constitucionalismo brasileiro e o paradigma da "roupa invisível" da interpretação positivista. In: CIARLINI, Alvaro Luis de A. S. Temas de jurisdição constitucional e cidadania: linguagem, racionalidade e legitimidade das decisões judiciais. v. 1.Brasília: IDP, 2014. Disponível em: <http://www.idp.edu.br/publicacoes/portal-de-ebooks>. Acesso em: 15 jun. 2015. 
DIMOULIS, Dimitri. Positivismo jurídico: introdução a uma teoria do direito e defesa do pragmatismo jurídico-político. São Paulo: Método, 2006.

FERNANDES, Ricardo Vieira de Carvalho; BICALHO, Guilherme Pereira Dolabella. Do positivismo ao pós-positivismo jurídico: o atual paradigma jusfilosófico constitucional. In: Revista de informação legislativa, v. 48, n. 189 (jan./mar. 2011). Disponível em: $<$ http://www2.senado.leg.br/bdsf/item/id/24286 4>. Acesso em 18 jun. 2015.

FINGER, Júlio César. Constituição e direito privado: algumas notas sobre a chamada constitucionalização do direito civil. In: SARLET, Ingo Wolfgang (org.) A constituição concretizada: construindo pontes com o público e o privado. Porto Alegre: Livraria do Advogado, 2000, p. 85-106.

GERVASONI, Tássia Aparecida; BOLESINA, Iuri. Constitucionalismo contemporâneo e hermenêutica: novas perspectivas, velhas dúvidas e o positivismo (solipsista) que anima o ativismo judicial no Brasil. In: BEÇAK, Rubens; BORGES, Alexandre Walmott; LOPES, Ana Maria D'Ávila. (Org.). Hermenêutica. 1. ed. Florianópolis: CONPEDI, 2014, v. 1, p. 169-192. Disponível em: <http://publicadireito.com.br/publicacao/ufsc/livro.php?gt=93>. Acesso em: 14 jun. 2015.

GERVASONI, Tássia Aparecida. Os lugares (e os problemas) da interpretação no Direito: da hermenêutica romântica de Schleiermacher aos primórdios do neoconstitucionalismo. In: BORGES, Alexandre Walmott; ADEODATO, João Maurício Leitão; TOLEDO, Iara Rodrigues de. (Org.). Hermenêutica - XXII Encontro Nacional do Conpedi. 1. ed.Florianópolis: FUNJAB, 2013, v. $1, \quad$ p. 461-485. Disponível em:<http://www.publicadireito.com.br/publicacao/unicuritiba/livr o.php?gt=93>. Acesso em: 14 jun. 2015.

GRAUS, Eros Roberto. O direito posto e o direito pressuposto. 3. ed. São Paulo: Malheiros, 2000.

HART, H. L. A. O conceito de direito. Trad. Antônio de Oliveira Sette-Câmara. São Paulo: WMF Martins Fontes, 2009, p. 323.

KELSEN, Hans. Teoria pura do direito. Trad.João Baptista Machado. 6. ed. São Paulo: Martins Fontes, 1998.

LIMA, Iara Menezes. Escola da Exegese. In: Revista Brasileira de Estudos Políticos, v. 97, 2008, pp. 105-122.

LUIZ, Fernando Vieira. Teoria da argumentação judicial: dos paradigmas de Ricardo Lorenzetti à resposta adequada à constituição de Lenio Streck. Porto Alegre: Livraria do Advogado, 2013.

MATOS, Andityas Soares de Moura Costa. A norma fundamental de Hans Kelsen como postulado científico. In: Revista da Faculdade de Direito UFMG, Belo Horizonte, n. 58, p. 41-84, jan./jun. 2011, p. 41-84. Disponível em: <http://www.direito.ufmg.br/revista/index.php/revista/article/view/136>.Acesso em: 20 jun. 2015. 
MAZOTTI, Marcelo. As escolas hermenêuticas e os métodos de interpretação da lei. Barueri: Minha Editora, 2010.

SHAW, Geoffrey C. H. L. A. Hart's lost essay: discretion and the legal process school. 2013. Disponível: <http://harvardlawreview.org/2013/12/h-1-a-harts-lost-essay-discretion-and-thelegal-process-school/>. Acesso em 18 jun. 2015.

STRECK, Lenio Luiz. O que é isto - decido conforme minha consciência? 2. ed. rev. e ampl. Porto Alegre: Livraria do Advogado, 2010.

O Brasil revive a Escola do Direito Livre! E dá-lhe pedalada na lei! In: Conjur. Disponível em: <http://www.conjur.com.br/2015-jun-25/senso-incomum-brasil-revive-escoladireito-livre-lhe-pedalada-lei>. Acesso em: 28 jun. 2015.

. Verdade e Consenso: constituição, hermenêutica e teorias discursivas. 4. ed. São Paulo: Saraiva, 2012.

WARAT, Luis Alberto. Mitos e teorias na interpretação da lei. Porto Alegre: Síntese ltda, 1979.

WIEACKER, Franz. História do direito privado moderno. 4. ed. Trad. A.M.Botelho Hespanha. Lisboa: Fundação Calouste Gulbenkian, 2010.

\section{Sobre os autores:}

Tamiris Alessandra Gervasoni é Mestranda com Bolsa Capes Prosup em Direito pela Universidade de Santa Cruz do Sul - UNISC. Graduada pela mesma instituição. Integrante do Grupo de Pesquisa "Direito, Cidadania e Políticas Públicas", coordenado pela Professora PósDoutora em Direito Marli Marlene Moraes da Costa. Endereço eletrônico: tamirisgervasoni@gmail.com

Iuri Bolesina é Doutorando e Mestre em Direito pela Universidade de Santa Cruz do Sul UNISC. Especialista em Direito Civil pela Faculdade Meridional - IMED. Integrante do Grupo de Pesquisa "Intersecções jurídicas entre o público e o privado", coordenado pelo Pós-Dr. Jorge Renato dos Reis, vinculado ao CNPq. Professor da faculdade de direito da Faculdade Meridional - IMED. Endereço eletrônico: iuribolesina@ gmail.com 